\title{
Phonetic Structures of Paiwan
}

\author{
Chun-Mei Chen \\ University of Texas at Austin
}

\section{Introduction}

\subsection{Goals of the research}

This study focuses upon a detailed description and analysis of the phonetic structures of Paiwan, an aboriginal language spoken in Taiwan, with around 53,000 speakers. Paiwan, a member of the Austronesian language family, is not typologically related to the other languages such as Mandarin and Taiwanese spoken in its geographically contiguous districts. Earlier work on phonological features of Paiwan (Chang, 1999; Tseng, 2003) sought an account in terms of segments and isolated facts about reduplication and stress, without accounting for the possible roles of phrase-level and sentence-level prosodic structures. Government Teaching Material (1993) listed 25 consonants and 4 vowels, without any description of phonetic features and phonological rules. Chang's (2000) reference grammar included 22 consonants and 4 vowels, with a very brief description of 5 phonological rules on single words. Regional diversity and 25 consonants have been mentioned in Pulaluyan's (2002) teaching material; however, no description of phonological rules was found in his material.

Maddieson (2001) has pointed out that the majority of field reports on languages give rather minimal details on their phonetic properties, sometimes nothing more than a list of symbols. Though the phonological inventory of Paiwan has been constructed in recent work (Chang, 2000; Pulaluyan, 2002), it varies from one fieldwork documentation to another. Verbal arts play an important role in communication among the ethnic members, but none of the existing documentation provides phonetic evidence for the prosodic structures. Consider the sentences listed in (1), (2) and (3).
(1) a. timafu mamazaninan.
'He is a chieftain.'
b. timaju mamazayinan.
'Is he a chieftain?'
(2) a. aitfiu ini ka suntfiu
'This is not the village head.'
b. aitfiu ini ka suntfiu
'Isn't this the village head?'
(3) a. timaju vulunvulun yana mamazaninan.
'He is an old chieftain.'
b. timaju vulunvulun yana mamazaninan.
'He is a very old chieftain.'


The distinction between (a) and (b) in (1)-(3) is based on prosodic structures. Work based on prosodic theory (Beckman, 1986; Pierrehumbert \& Beckman, 1988; Pierrehumbert \& Talkin, 1992; Pierrehumbert, 1995; Fox 2000) has shown that prosodic prominence is an important factor in the description of many phonetic phenomena. The phonetic manifestation of prosodic contrasts usually involves characteristic fundamental frequency patterns, and interactive contribution from stress, duration, pitch and syllables.

This study provides description and examination for the following issues: (i) consonant inventory; (ii) vowel inventory, (iii) $(\mathrm{C}) \mathrm{V}(\mathrm{V})(\mathrm{C})$ syllable structure; (iv) stress and the interaction between vowel length, contrastive ratios, pitch and accent; ( $v$ ) intonation, pitch patterns in sentences with different syntactic structures. The fieldwork reported here assesses the nature of the sounds of the Austronesian language, though it may be the last to record systematic data from a reasonable sample of Paiwan speakers. Voice data is digital recording of single words, phrases, sentences and discourse. Phonetic Measurements include vowelquality plots, f0 and relative formant locus, vowel duration, phonetic correlates of stress, pitch track of intonation and accentuation. The goals of the study are to provide a detailed description and analysis of the phonetic structures of Paiwan and to provide empirical evidence for descriptive and theoretical documentation of the Austronesian language.

\subsection{Background information}

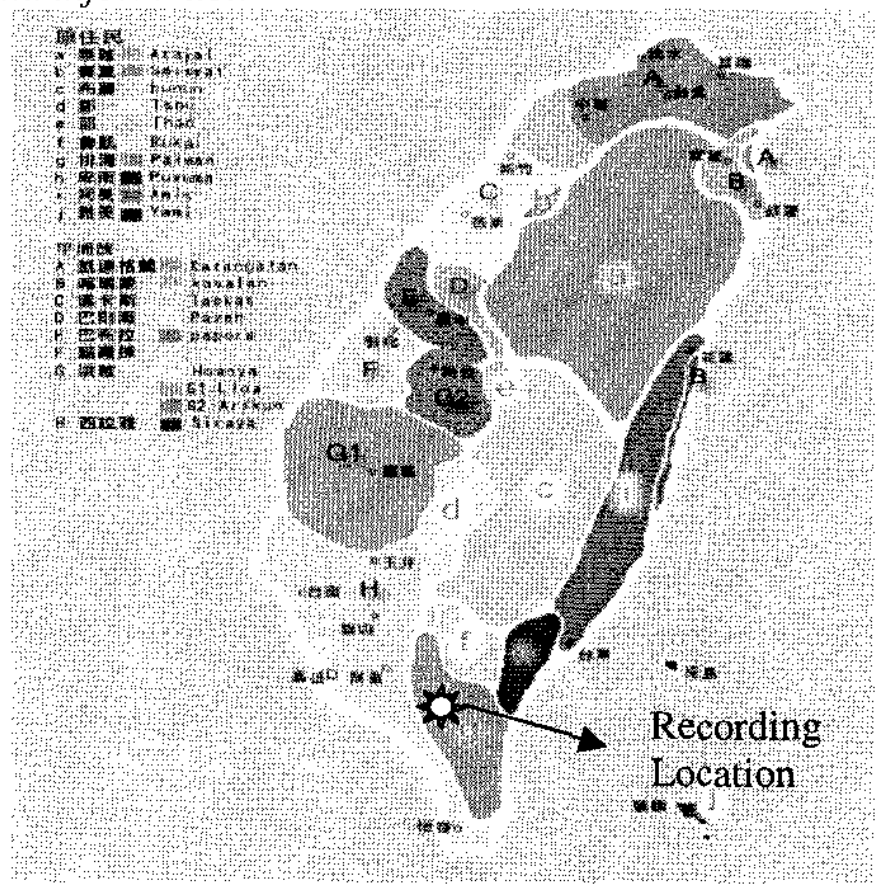

Figure 1: Distribution of Austronesian Languages in Taiwan

Source: http://www.ocac.net/newocac/taiwan/taiwan_6-3.htm\#

The language community where we collected data is Piuma tribe, Pingtung County. The tribe is surrounded by mountains. More than $90 \%$ of the 
residents in the community are Paiwan aborigines. Non-Paiwan residents in the community are mainly spouses of Paiwan aborigines. Paiwan is the primary communication language in the tribe. However, the young generation speaks Mandarin in public educational institutions and Taiwanese outside of the tribe. Shown in Figure 1, the recording location is marked by an asterisk.

The informants are two male and one female Paiwan speakers, ages 48-68. All of them speak very fluent Paiwan. All the oral data in this study is based on natural speech, elicitation, narratives, and conversation.

\section{Consonants}

\subsection{Descriptive consonant inventory}

The consonant inventory of Paiwan is shown in Table 1 . Note that $/ \mathrm{ts} /$ is the only affricate found in Paiwan. /ts/ may be a phoneme in contact with Mandarin and Taiwanese. Many other Austronesian languages such as Fijian, Javanese, Malay and Tagalog do not have this affricate phoneme. Wolff (1988) has claimed that in the languages outside Formosa ${ }^{*} t$ and ${ }^{*} \mathrm{C}$ merged. The phoneme /ts/ is found only in Formosan Atayalic and Paiwanic languages.

Table 1: Paiwan consonants

\begin{tabular}{|c|c|c|c|c|c|c|c|}
\hline & Bilabial & Alveolar & Retroflex & Palatal & Velar & Uvular & Glottal \\
\hline Plosive & $b$ & $\mathrm{~d}$ & $d$ & $\begin{array}{cc}c^{1} & f\end{array}$ & $\mathrm{k}$ & $q$ & $?$ \\
\hline Fricative & $\mathrm{v}$ & $z$ & & & & & $\mathrm{~h}$ \\
\hline Affricate & & ts & & & & & \\
\hline Trill & & $\mathrm{r}$ & & & & & \\
\hline Nasal & $\mathrm{m}$ & $\mathrm{n}$ & & & y & & \\
\hline $\begin{array}{l}\text { Approxi } \\
\text { mant }\end{array}$ & w & 1 & l & $j$ & & & \\
\hline
\end{tabular}

Shown in Table 1, Paiwan has alveolar, palatal, velar and uvular stops. Quite a few glottal stops [?] at word-initial position were also found. There is dialectal variation between [q] and [?]. For instance, qilas 'moon' is pronounced as Pilas 'moon' in Northern Paiwan villages. Fieldwork based on Northern Paiwan (Chang, 2000) does not include the phoneme /q/. On the other hand, Government Teaching Material (1993) does not include glottal stop / $/$, only / $q$ / is found. Many words starting with uvular $/ \mathrm{q} /$ have free alternation of $/ \mathrm{k} /$ in the other dialects (Pulaluyan, 2000). In Piuma tribe, although both $/ q /$ and $/ 2 /$ are found, they are free alternation.

${ }^{1}[\mathrm{c}]$ and $[\mathrm{j}]$ are transcribed as [t] and [dj] in earlier Austronesian literature. 


\subsection{Palatalization}

Palatalization is found in Paiwan. This phonological rule is represented in (4).

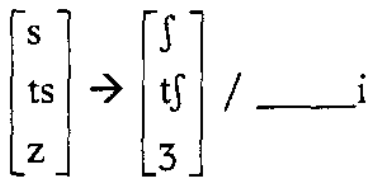

It is interesting that palatalization in the Piuma tribe is optional in many cases. For instance, 'human beings' in Paiwan is 'tsaotsao'. The female informant always pronounces it as 't tiaot fiao', in which case palatalization occurs. It is possible that $/ \mathrm{ts} /$ is the reflex of $/ \mathrm{c} /$.

\subsection{Retroflexion}

Paiwan has alveolar [d], [1] and retroflex [d], [l], as shown in Table 1. A minimal pair for $/ 1 /$ and $/ /$ was found, as in alu 'honey' and alu 'eight'. However, we did not find any minimal pairs for $/ \mathrm{d} /$ and $/ \mathrm{d} /$, though dusa 'two' is a basic numeral in Paiwan. Ferrell (1980) has argued that only one Formosan language, Paiwan, has a phoneme inventory directly comparable to the Proto-Austronesian (PAN) inventory proposed by Dahl (1973). All of the Formosan languages, including Paiwan, have made extensive mergers and splits among sonorants and laterals; and all Formosan languages except Paiwan have also made extensive mergers and splits among non-peripheral obstruent segments. Paiwan is unique in being the only Formosan language which does not merge any of the segments $*^{*} \mathrm{t}$ and ${ }^{*} \mathrm{~d}$ under his examination. On the other hand, though earlier study (Wolff, 1988) has proposed that retroflexion may not be a distinctive feature in Paiwan, we did find the minimal pair for $/ V$ and $/ /$. Thus, we claim that retroflexion is a distinctive feature in Paiwan.

\section{Vowels}

3.1 Descriptive vowel inventory

The vowel inventory of Paiwan is shown in (5).

(5)

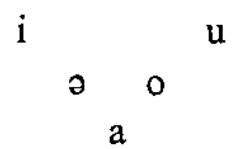

Paiwan has a five-vowel system, though the back mid vowel /o/ may be a product of language contact. The occurrence frequency of vowel phoneme $/ \mathrm{o} /$ is only $3 \%$, whereas the relative occurrence of $/ a /$ is the most frequent, as high as $39 \%$. Blust (1988) has noted that almost all Austronesian specialists admit just four Proto-Austronesian vowels: $a, \partial, i$ and $u$. Though many of the words with phoneme /o/ are associated with Mandarin, Taiwanese or Japanese loanwords, /o/ 
also serves for basic lexicon of body parts such as throat ' $l i 3 o$ ', waist 'fioc', kidney ' $p u l o$ ', and ankle ' $t$ imomuwu' in Piuma Paiwan. Therefore, we include /o/ in our vowel inventory. On the other hand, we did not find any vowel length as a distinctive feature in our corpus. Paiwan vowels after voiceless stops at four places of articulation are shown in Table 2. All tokens selected were extracted from elicitation. Each token was repeated twice. There were a total of forty tokens measured to get the formants of the main vowels.

Table 2: Words exemplifying contrasts among Paiwan vowels

\begin{tabular}{|c|c|c|c|c|c|}
\hline Bilabial & & Iveolar & & Velar & Uvular \\
\hline $\begin{array}{ll}\text { pi pida } & \\
& \text { 'how many' }\end{array}$ & $\mathbf{t i}$ & $\begin{array}{l}\text { tisun } \\
\text { 'you' }\end{array}$ & ki & $\begin{array}{l}\text { kina } \\
\text { 'mother' }\end{array}$ & $\begin{array}{ll}\text { qi } & \text { qilas } \\
& \text { 'moon' }\end{array}$ \\
\hline $\begin{array}{l}\text { pu pumaya } \\
\text { 'it doesn't matter' }\end{array}$ & tu & $\begin{array}{l}\text { tutu } \\
\text { 'breasts' }\end{array}$ & ku & $\begin{array}{l}\text { kudakudal } \\
\text { 'big' }\end{array}$ & $\begin{array}{l}\text { qulivanrau } \\
\text { 'rainbow' }\end{array}$ \\
\hline $\begin{array}{l}\text { pa pavai } \\
\text { 'to give' }\end{array}$ & ta & $\begin{array}{l}\text { takit } \\
\text { 'sword' }\end{array}$ & $\mathbf{k a}$ & $\begin{array}{l}\text { kama } \\
\text { 'father' }\end{array}$ & $\begin{array}{l}\text { qa qaropus } \\
\text { 'cloud' }\end{array}$ \\
\hline $\begin{array}{c}\text { po ponana? } \\
\text { 'shoot' }\end{array}$ & to & $\begin{array}{l}\text { tamakəl, } \\
\text { 'to drink' }\end{array}$ & kə & $\begin{array}{l}\text { kəmolay } \\
\text { 'to know' }\end{array}$ & $\begin{array}{l}\text { qə qəmudal } \\
\text { 'to rain' } \\
\end{array}$ \\
\hline $\begin{array}{ll}\text { po } & \begin{array}{l}\text { kipo }^{2} \\
\text { 'soil' }\end{array}\end{array}$ & & $\begin{array}{l}\text { tola } \\
\text { 'eel' }\end{array}$ & ko & $\begin{array}{l}\text { kolo } \\
\text { 'head' }\end{array}$ & $\begin{array}{l}\text { qo qolivaivai } \\
\text { 'Korean oriole' }\end{array}$ \\
\hline
\end{tabular}

A plot of formant values of Paiwan main vowels is illustrated in Figure 2. Tongue position for $/ \mathrm{u} /$ is slightly lower than that for the front high vowel $/ \mathrm{i} /$.

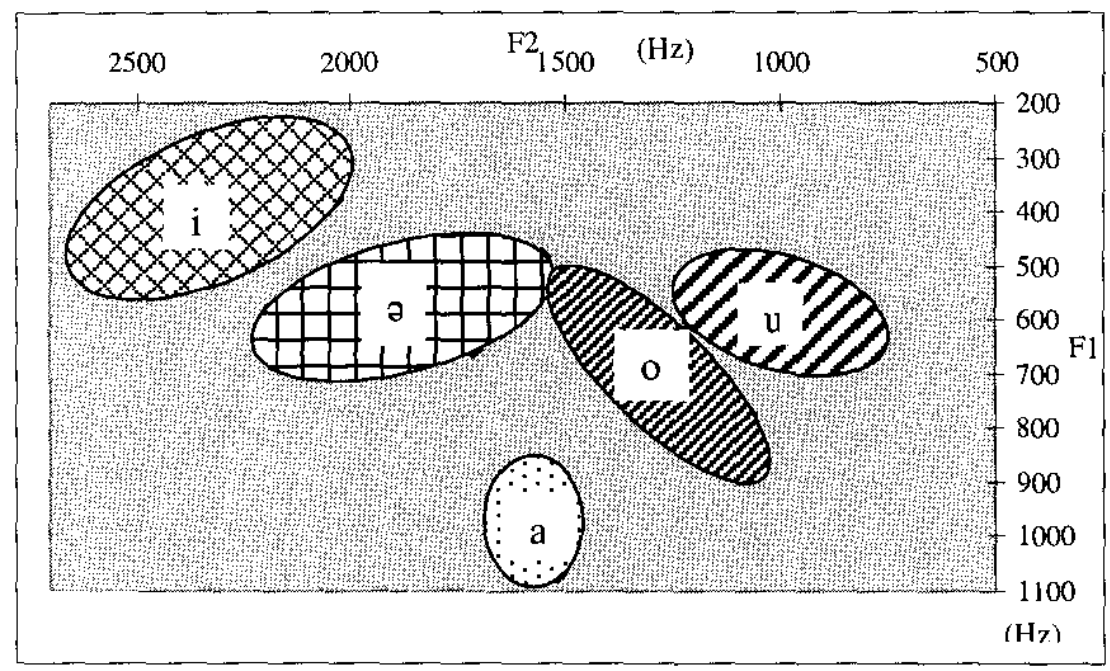

Figure 2: Formant Plot of Paiwan Main Vowels

\footnotetext{
${ }^{2}$ We could not find any token with the CV combination 'po' at word-initial position. The only token we found in the corpus is the word 'kipo' ('soil').

3 'head' can be 'kolo', '?ulu', or 'ulu'.
} 
The length of a diphthong is not longer than that of a single vowel. Neither does a diphthong affect the assignment of stress.

\section{Syllable Structure}

Paiwan syllable structure is $(\mathrm{C}) \mathrm{V}(\mathrm{V})(\mathrm{C})$. The metrical syllable structure of Paiwan is illustrated in (6).

(6)

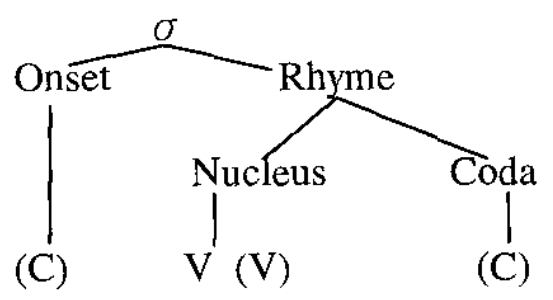

Words with multiple syllables are not rare in Paiwan. Syllabification is based on syllable structure $(\mathrm{C}) \mathrm{V}(\mathrm{V})(\mathrm{C})$. In the long word mamazayinan 'chieftain', for example, syllabification was made as shown in Table 3 . The penult syllable was found to be longer and with higher pitch than the other syllables.

Table 3: Phonetic realization of mamazaninan 'chieftain'

\begin{tabular}{|l|c|c|c|c|c|}
\hline \multicolumn{7}{|c|}{ mamazaninan = CV.CV.CV.CV.CVC } \\
\hline Elicitation & $\mathrm{CV}$ & $\mathrm{CV}$ & $\mathrm{CV}$ & $\mathbf{C V}$ & $\mathrm{CVC}$ \\
\hline Duration (msec) & 173 & 136 & 185 & $\mathbf{2 1 6}$ & 157 \\
\hline Percentage & $20 \%$ & $16 \%$ & $21 \%$ & $\mathbf{2 5 \%}$ & $18 \%$ \\
\hline Pitch (HZ) & 132 & 122 & 121 & $\mathbf{1 4 9}$ & 117 \\
\hline Feature & $\mathrm{H}^{*}$ & Low & Low & Peak & Low \\
\hline
\end{tabular}

Reduplication is also a morphological process to make long syllables. But it does not affect syllabification. On the other hand, affixation of vowel [a] may result in re-syllabification. Phonetically, liaison occurs whenever vowel [a] is inserted between lexical words, regardless of the preceding segments. Even if the preceding segment is also an [a], there is no lengthening. The example of numeral syllabification is shown in Table 4, in which liaison of affix [a] is always found.

Table 4: Syllabification of Paiwan numerals

\begin{tabular}{|l|l|l|l|l|}
\hline Paiwan & Gloss & Paiwan & Gloss & Syllabification \\
\hline $\begin{array}{l}\text { dusa } \\
\text { CVCV }\end{array}$ & two & $\begin{array}{l}\text { dusa a pulu? } \\
\text { CVCV+V+CVCVC }\end{array}$ & twenty & $\begin{array}{l}\text { du.sa.pu.lu? } \\
\text { CV.CV.CV.CVC }\end{array}$ \\
\hline $\begin{array}{l}\text { unəm } \\
\text { VCVC }\end{array}$ & six & $\begin{array}{l}\text { unəm a pulu? } \\
\text { VCVC+V+CVCVC }\end{array}$ & sixty & $\begin{array}{l}\text { u.nə.ma.pu.lu? } \\
\text { V.CV.CV.CV.CVC }\end{array}$ \\
\hline $\begin{array}{l}\text { pitu } \\
\text { CVCV }\end{array}$ & seven & $\begin{array}{l}\text { pitu a pulu? } \\
\text { CVCV+V+CVCVC }\end{array}$ & seventy & $\begin{array}{l}\text { pi.tua.pu.lu? } \\
\text { CV.CVV.CV.CVC }\end{array}$ \\
\hline
\end{tabular}




\begin{tabular}{|l|l|l|l|l|}
\hline $\begin{array}{l}\text { daidai } \\
\text { CVVCVV }\end{array}$ & $\begin{array}{l}\text { one } \\
\text { hundred }\end{array}$ & $\begin{array}{l}\text { pitu a idai } \\
\text { CVCV+V+VCVC }\end{array}$ & $\begin{array}{l}\text { seven } \\
\text { hundred }\end{array}$ & $\begin{array}{l}\text { pi.tua.i.dai } \\
\text { CV.CVV.V.CVC }\end{array}$ \\
\hline
\end{tabular}

\section{Stress}

\subsection{Descriptive Stress Patterns}

Paiwan stress falls on penultimate syllables in general. However, there are a few exceptions. Our description of Paiwan stress is in (7).

(7) a. In CV or CVCV syllables, stress falls on the first V $(\sigma \leq 2)$

b. Stress falls on the penultimate syllable elsewhere $(\sigma>2)$

c. Stress patterns are fixed in content words but not fixed in function words, reduplicated and affixed forms.

d. If the nucleus of the penultimate syllable is a weak schwa [o], stress shifts to the last syllable; when both penultimate and last nuclei are schwa [ə], stress falls on the last [ə].

Earlier work on Proto-Austronesian (PAN) stress mainly focuses on comparison and reconstruction. Wolff (1993) has proposed that PAN roots had a stress contrast in the final two syllables of the root. He argues that in PAN the stress patterns fell on the penult of the root if it was long and on the final syllable of the root if the penult was short. Nevertheless, no further description of the interaction between vowel quality and stress patterns was found in his study. In fact, vowel length is a phonetic realization or a correlate of stress, rather than a prerequisite to trigger stress. On the other hand, affixation has been found to affect stress in earlier PAN studies (Wolff, 1993; Zorc, 1993). There was the phenomenon of accent shift whereby the affixed form had the accentual pattern opposite to the pattern of the root. This is true for Paiwan stress, as we have described in (7c) that stress in affixation is not fixed.

Syntactic classes in Paiwan, as far as we have observed, do not affect the assignment of stress in Piuma Paiwan. Stress falls on the penult in numerals and free pronouns. As we have described in (7d), stress never falls on a schwa, unless the schwa is the final syllable. Sample words are shown in (8). Stress shifts to the last syllable when the penultimate syllable is a schwa. Shown in (8b) and (8c), when schwa [o] is in both penultimate and final nuclei, stress falls on the last [o].

\begin{tabular}{|c|c|c|}
\hline & Paiwan & Gloss \\
\hline a. & $\begin{array}{l}\text { kəmolan } \\
\text { [CVCVCVC] }\end{array}$ & 'to know' \\
\hline b. & $\begin{array}{l}\text { masəysəy } \\
{[\mathrm{CVCVCCVC}]}\end{array}$ & 'to work' \\
\hline c. & $\begin{array}{l}\text { mipərəpər } \\
{[C V C V C V C V C]}\end{array}$ & 'to fly' \\
\hline
\end{tabular}

$\underline{\text { Stress }}$

$$
\left[\begin{array}{lll}
\sigma & \sigma & \sigma^{\prime}
\end{array}\right]
$$$$
\text { (x) }
$$$$
\left[\begin{array}{lll}
\sigma & \sigma & \sigma^{\prime}
\end{array}\right]
$$

$\left[\begin{array}{llll}\sigma & \sigma & \sigma & \sigma\end{array}\right]$ 


\subsection{Phonetic Correlates of Paiwan Stress}

Acoustic correlates of stress in English have been widely studied. Fry $(1955,1958)$ investigated the acoustic and perceptual correlates of lexical stress in English noun/verb word-pairs. Following his hierarchy, duration is a more effective cue to stress than intensity, and pitch is an even more effective cue than duration. However, as early as Berinstein (1979), it has been disclosed that languages with phonemic length do not use duration as a correlate of stress. Moreover, pitchaccent languages such as Japanese use pitch as a correlate of stress to a greater extent than English (Beckman 1986). While whether the conclusions of these studies can apply to Paiwan is unknown, it is clear that phonetic cues to stress in different languages can vary.

As we have seen in section 3.1, vowel length is not phonemic in Paiwan, and tonal feature is not distinctive in this language. Three phonetic cues to stress were selected here: vowel duration, pitch and intensity. We propose the following hypotheses of Paiwan stress in (9).

\section{(9) a. Stressed syllables have longer DURATION \\ b. Stressed syllables have higher PITCH \\ c. Stressed syllables have greater INTENSITY}

In the following section, contrast of stressed and unstressed syllables will be examined to test the hypothesis of Paiwan stress correlates.

\subsection{Contrast of Stressed and Unstressed Syllables}

Figure 3 illustrates the duration contrast between stressed vowel and unstressed vowels. In syllables more than two morae $(>2 \sigma \mathrm{s})$, the duration was measured from penultimate vowel and final vowel in stressed and unstressed positions. In three and five-mora syllables, when stressed, duration of a vowel is more than twice that of an unstressed vowel. The duration of a stressed vowel is overall longer than an unstressed one, more than 1.7 times that of an unstressed vowel. It is clear that duration is a correlate of Paiwan stress.

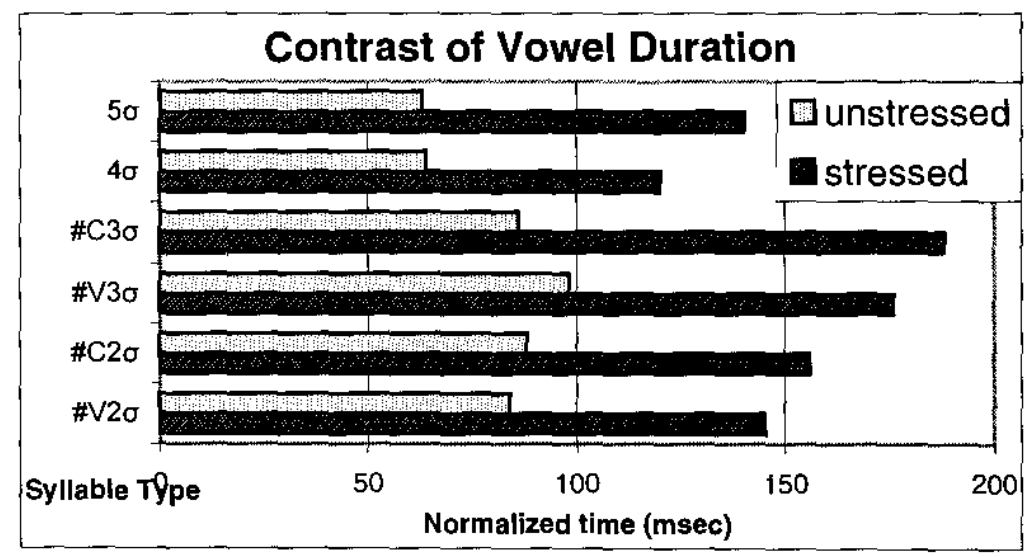

Figure 3: Vowel Length Contrast of Stressed and Unstressed Syllables 
As far as pitch is concerned, stressed vowels were perceived to have higher pitch. Figure 4 summaries the means for pitch values in stressed and unstressed positions. Pitch values were measured at the midpoint of each syllable. In syllables with more than two moraes, pitch contrast was measured at penultimate and final vowels of each token.

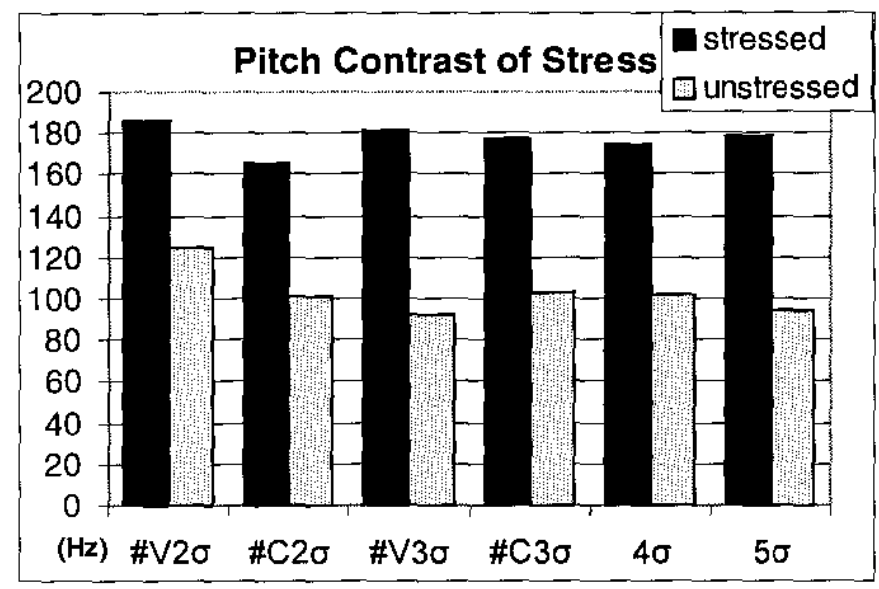

Figure 4: Pitch Contrast of Stressed and Unstressed Syllables

All the stressed vowels measured have higher pitch than the unstressed vowels, as shown in Figure 4. The hypothesis that stressed syllables have higher pitch is therefore verified. Note that in multiple syllables $(>5 \sigma \mathrm{s})$, stress is more correlated with stress than duration. Multiple syllables are usually compound words, such as 'eleven': dapulu? saga ita. Vowel contrast in compound words is not as apparent as that in single words. Vowel duration in the final position of compound words is usually longer, regardless of stress. Even though duration contrast is neutralized in multiple syllables, pitch contrast in stressed and unstressed positions is retained.

However, the intensity contrast between stressed and unstressed syllables is not consistent in all the syllable types. This indicates intensity may not be a robust correlate of Paiwan stress, at least, less correlated than duration and pitch. Thus, our hypothesis in (9c) may not be true. Unstressed final syllables may have greater intensity than stressed penultimate syllables.

\subsection{Emphatic Degree Accentuation}

Emphatic degree accentuation was found in Paiwan discourse. This type of accentuation can be found in many other languages. Emphatic accentuation in Paiwan is used not only to signal the degree of intensity but also to function as different degree of semantic lexicon. For instance, 'very old' has longer duration and higher F0 than 'old'. There is no degree adverb 'very' or 'extremely' in Paiwan lexicon. The most common way to denote the meaning of 'very' is either to reduplicate stems or by means of prosodic prominence. In the case of vuluyvuluy 'old', since it is already a reduplicated form, the distinction between 
'old' and 'very old' is thus imposed on prosodic elements. The contrast of pitch

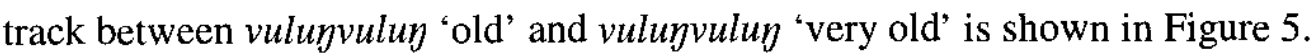

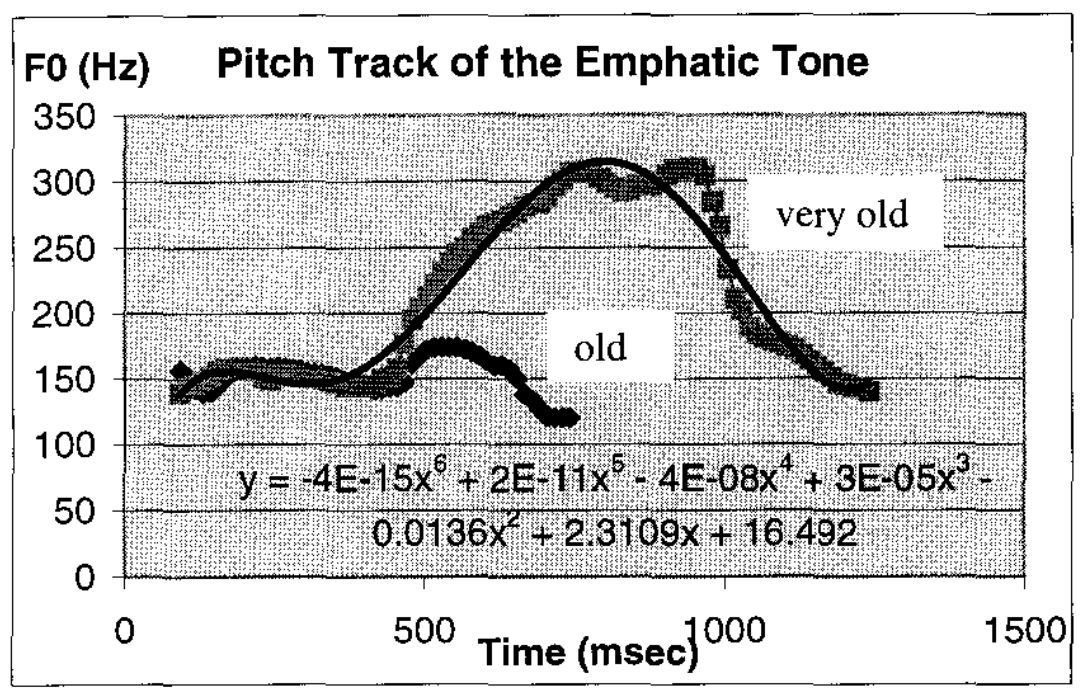

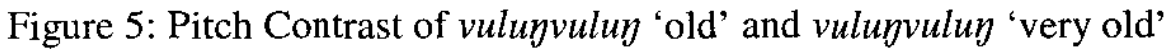

Emphatic accentuation results in longer duration of the reduplicated vowels, as shown in Figure 5. The reduplicated vowel RV1 at penultimate position has the most significant lengthening, around 1.35 times that of an unaccented vowel. However, accentuation does not lengthen the relative duration of the other vowels in stems. Lengthening is most apparent in reduplicated vowels at syllable-penultimate position.

Emphatic accent has higher pitch than the control one. Higher pitch is most apparent in the penultimate-syllable position. On the other hand, amplitude is not correlated with accentuation. Emphatic vowels do not have greater intensity than the control ones. This indicates intensity is not a correlate of Paiwan accent.

In summary, emphatic accentuation signals both degree of intensity and distinctive levels of degree. Emphatic accent in Paiwan is realized as higher pitch and longer duration. Intensity is not a correlate of emphatic accentuation.

\section{Intonation}

\subsection{Descriptive Intonation}

We described the intonation types of Paiwan in terms of features. The distinctive features in our description include shape of pitch contour, starting/ending points of pitch contour, pitch range, transition, rising and falling.

The most distinctive intonation in Paiwan is the feature at the ends of a declarative and a yes/no question. Declarative sentences in Paiwan usually have falling ending pitch. Yes/no questions, on the other hand, are marked by high rising pitch. Neither does a question marker nor movement of auxiliaries form a yes/no question in Paiwan. Though there are some WH-words in Paiwan such as ima 'who', nama 'what', inu 'where/which', kamuda 'how', aku (a zua) 'why', 
there is no question marker except for one particle borrowed from Taiwanese. The differences between declaratives and yes/no questions are in the $\mathrm{H}^{*} \mathrm{~L}$ higher starting points and the LH\% high pitch at the final-nuclear position of the questions. Intonation in declarative and yes/no question is correlated with the presence of the final rising. Peak at sentential-penultimate position is retained in the declaratives with emphatic accent. Note that questions in Paiwan are correlated with a rising ending, excluding WH-Questions. The typological description of question intonation in Paiwan is summarized in (10).

a. Types of questions with a rising ending:

(i) Yes/No: Is he a chieftain?

(ii) Rhetorical: He is a chieftain, isn't he?

(iii) Alternative: Is he a chieftain or village head?

b. Types of questions with a falling ending: WH-Questions

Where, When, What, Who, How, Why

In the following section, four types of intonation will be analyzed: declarative, yes/no question, WH-questions and negation. Gaps caused by voiceless segments in pitch tracks were not avoided, because the recording process was not experimental-designed. All the sentences were collected from natural speech.

\subsection{Pitch tracks of sentences}

The typical contrast between declaratives and yes/no questions is shown in (1) and (2). A pitch track of the sentences in (1) shows the distinctive prosodic structures of intonation. Declaratives have a distinct pitch contour from yes/no questions. The pitch contrast of the sentences in (1) is illustrated in Figure 6.

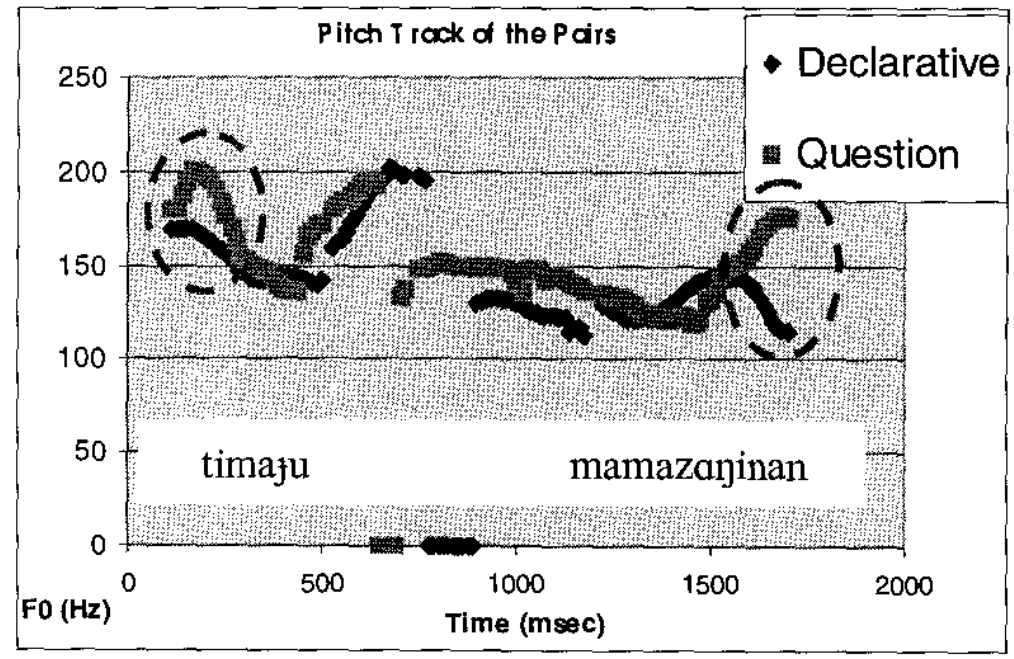

Figure 6: Pitch Tracks of timaju mamazayinan

Shown in Figure 6, yes/no question has a higher starting point and a rising ending $\mathrm{LH} \%$. Notice the slight dropping before the final rising. All the yes/no 
questions examined have this dropping before the final rising. The rising ending feature of yes/no question is retained even in embedded questions. For instance, in the embedded yes/no questions such as 'he asked me if he is a chieftain (is he a chieftain)' or 'can you tell me if people in the village know he is a chieftain', the final content word mamazayinan 'chieftain' still keeps the rising ending. Prosodic features do play an important role in Paiwan discourse and conversation.

Negation sentences have very similar pitch contours to declarative intonation, with a falling ending. The negation word ini-ka 'not' does not have any particular rising or falling prosodic feature. When the negation word ini-ka 'not' is placed at the end of a declarative sentence, it forms a rhetorical question, such as timafu mamazaninan ini 'he is a chieftain, isn't he?' The intonation of a rhetorical question is very different from negation intonation. A pitch track of a rhetorical question is illustrated in Figure 7.

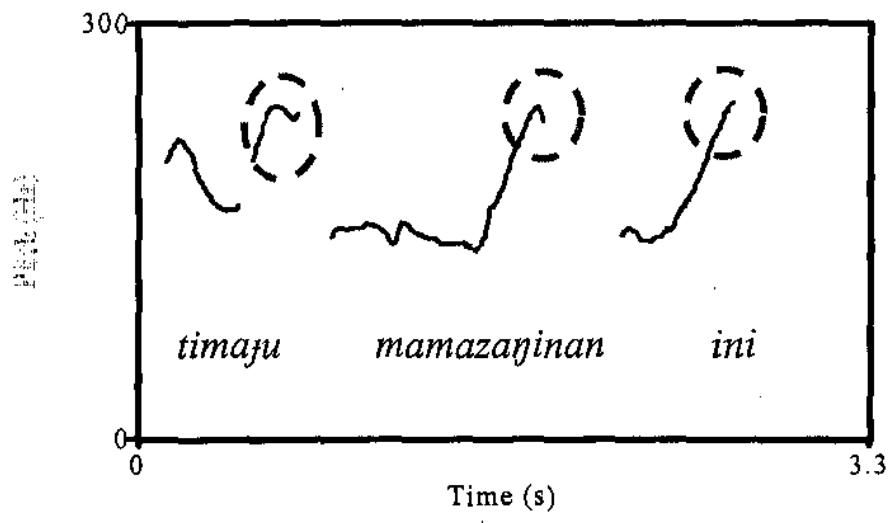

Figure 7: Pitch Track of timafu mamazaninan ini

Shown in Figure 7, not only the negation word ini 'not' but also the other content words have rising boundary tone $\mathrm{H} \%$. Pitch range is not a correlate of intonation typology, as it varies from one pair to another.

As shown in (10a), the third type of question with a rising ending is alternative. In Paiwan, alternative word manu 'or' is placed between two alternatives. All the content words in the alternative sentence have a rising boundary tone $\mathrm{LH} \%$, which indicates all the content words are affected by the interrogative tone, and the sentence ends with a rising tone. The intonation peak usually falls on the second nucleus of the alternative word manu 'or'.

Finally, we analyzed the intonation pattern of WH-Questions. As we have described in (10b), WH-questions end with a falling tone. Pitch tracks of WHquestions show that intonation peak falls on WH-words, with or without affixation. Examples of WH-questions are shown in (11). Pitch tracks of the sentence are illustrated in Figure 8.

a. a nəma hokan

'What do you like to eat?' 

b. inu a gakiduluwan
'Where is the school?'
c. ma-inu-sun
'Where are you going?'

Shown in Figure 8, intonation peaks fall on the second syllables of WHwords noma 'what' and inu 'where'. Unlike other types of questions with a rising ending, WH-questions end with a falling tone. The features of WH-questions are summarized as follows: a falling ending and intonation peak on WH-words.

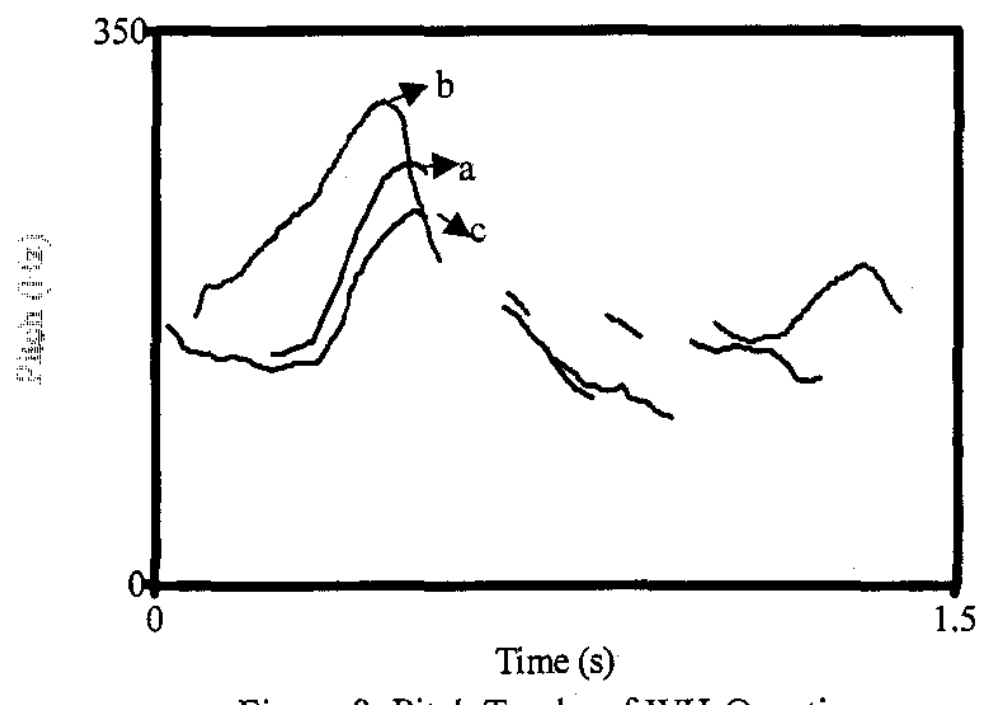

Figure 8: Pitch Tracks of WH-Questions

\section{Conclusion}

In this study, consonants, vowels, syllable structure, stress and intonation in Paiwan were examined. Consonant inventory, five-main vowels, formant plot of Paiwan main vowels have been illustrated. Paiwan has bilabial, alveolar, palatal, velar, uvular and glottal stops. Syllabification in Paiwan is based on syllable structure $(\mathrm{C}) \mathrm{V}(\mathrm{V})(\mathrm{C})$. The penult syllable was found to be longer and with higher pitch than the other syllables in a prosodic word.

It has been shown that phrase-level and sentence-level prosodic features play important roles in Paiwan. In phrase-level of prosody, penultimate stress and non-stress accent have been investigated. In sentence-level, both declarative intonation and interrogative intonation have been examined. Paiwan stress falls on penultimate syllables, if the prosody word is a stem. Stress patterns are fixed in content words but not fixed in function words. Weak schwa [ə] may result in stress shift to the final syllable, if the final syllable is not a schwa.

Vowel length is not phonemic in Paiwan. The hypotheses of Paiwan stress were verified. Duration and pitch are correlates of Paiwan stress. Stressed syllables have longer duration. All the stressed vowels measured have higher 
pitch than the unstressed vowels. However, the intensity contrast between stressed and unstressed syllables is not consistent. Emphatic accentuation in Paiwan signals both degree of intensity and distinctive levels of degree. Emphatic accent in Paiwan is realized as higher pitch and longer duration. Intensity is not a correlate of emphatic accentuation.

Intonation in Paiwan questions has been categorized into two types, with a rising ending or a falling ending. Types of questions with a rising ending include yes/no questions, rhetorical questions and alternative questions. Questions with a falling ending include WH-Questions. Declarative and negation sentences have a falling ending. Negation sentences have very similar pitch contour to declarative intonation. Questions in Paiwan are correlated with a rising tone; pitch peak falls on WH-words. Yes/no question has higher starting points and a rising ending $\mathrm{LH} \%$. The rising ending feature of yes/no question is retained even in embedded questions. In rhetorical questions, not only the negation word ini 'not' but also the other content words have rising boundary tone $\mathrm{H} \%$.

Thus far, empirical study of Austronesian prosodic structure is relatively rare, and the discussion on the typology of Formosan prosody is even less. We need more detailed description and studies on Formosan languages, not only Paiwan but also other endangered aboriginal languages.

\section{Endnotes}

ACKNOWLEDGEMENT: I thank the people in the Piuma Paiwan village for being supportive and helpful towards me. Special thanks go to Cegaw, who made my first fieldwork trip possible. I thank Vigong, Bailis and Mr. Kong for support and hospitality in the conference center of the village.

\section{References}

BECKMAN, MARY E. 1986. Stress and Non-Stress Accent. The Netherlands: Foris Publications Holland.

BERINSTEIN, A. 1979. A Cross-Linguistic Study on the Perception and Production of Stress. UCLA Working Papers in Phonetics 47, UCLA.

BLUST, ROBERT A. 1988. Austronesian Root Theory. Philadelphia: John Benjamins Publishing Company.

CHANG, XIU-JUAN. 2000. Paiwan Yu Cankao Yufa [Paiwan Reference Grammar]. Taipei: Yuanliu Quban ShiyeYiouxian Gongse [Yuanliu Publishers].

DAHL, OTTO C. 1973. Proto-Austronesian. Lund, Sweden: Scandanavian Institute of Asian Studies, Monograph Series No.15.

FERRELL, RALEIGH. 1980. Phonological Subgrouping of Formosan Languages. Austronesian Studies: Papers from the Second Eastern Conference on Austronesian Languages, ed. by Paz B. Naylor, 241-254. Michigan: Ann Arbor. 
FOX, ANTHONY. 2000. Prosodic Features and Prosodic Structure. Oxford: Oxford University Press.

FRY, D. B. 1955. Duration and Intensity as Physical Correlates of Linguistic Stress. Journal of the Acoustical Society of America 27: 155-58.

-1. 1958. Experiments in the Perception of Stress. Language and Speech 1: 126-152.

MADDIESON, IAN. 2001. Phonetic fieldwork. Linguistic Fieldwork, ed. by Paul Newman and Martha Ratliff, 211-229. Cambridge: Cambridge University Press.

PIERREHUMBERT J. \& M. BECKMAN. 1988. Japanese tone structure. Cambridge, MA: MIT Press.

PIERREHUMBERT J. \& TALKIN. 1992. Lention of $/ \mathrm{h} /$ and glottal stop. Papers in laboratory phonology Il: gesture segment prosody, ed. by G. Doherty and D. R. Ladd, 90-117. Cambridge: Cambridge University Press.

PIERREHUMBERT J. 1995. Prosodic effects on glottal allophones. Vocal fold physiology: voice quality control, ed. by O. Fujimura and M. Hirano, 3960. San Diego: Singular Publishing Group.

PINGTUNG COUNTY GOVERNMENTT, 1993. Pingtung Xian Muyu JiaocaiPaiwan Yu [Native Language Teaching Material of Pingtung CountyPaiwan]. Taiwan: Pingtung.

PULALUYAN, TALIGU. 2000. Pinaiwanan [An Introduction to Paiwan]. Printed in Taipei.

ROSS, MALCOLM. 2002. The History and Transitivity of Western Austronesian voice and Voice-Marking. The History and Typology of Western Austronesian Voice Systems, ed. by Fay Wouk and Malcolm Ross, 17-62. Australia: The Australian National University.

TSENG, MEYLYSA. 2003. Reduplication as Affixation in Paiwan. Presented in Austronesian Formal Linguistics Association Tenth Annual Meeting, University of Hawaii at Manoa.

WOLFF, JOHN U. 1988. The PAN Consonant System. Studies in Austronesian Linguistics, ed. by Richard McGinn, Monographs in International Studies Southeast Asia Series No. 76, 125-147. Ohio: Ohio University Center for Southeast Asian Studies.

-. 1993. Proto-Austronesian Stress. Tonality in Austronesian Languages, ed. by Jerold A. Edmondson and Kenneth J. Gregerson, 1-15. University of Hawaii Press.

ZORC, DAVID. 1993. Overview of Austronesian and Philippine Accent Patterns. Tonality in Austronesian Languages, ed. by Jerold A. Edmondson and Kenneth J. Gregerson, 17-24, University of Hawaii Press.

\section{CHUN-MEI CHEN}

University of Texas at Austin

Department of Linguistics, University of Texas at Austin, Austin, TX78741

USA

chench@mail.utexas.edu 